\title{
PRELIMINARY OBSERVATIONS ON THE CHEMICAL METHOD FOR THE DETECTION OF OVULATION
}

\author{
A. M. PHADKE, K. TILAK AND K. PADUKONE \\ Family Welfare Bureau, Bombay 4, India
}

(Received 10th April 1961)

\begin{abstract}
Summary. Recently, Sevag \& Colton (1959) published a chemical test for detecting the precise day of ovulation. We have performed this test in 112 menstrual cycles of sixty women. Out of 112 menstrual cycles studied, in fifty-six menstrual cycles $(50 \%)$ the chemical patterns were atypical. We do not substantiate the claim of Sevag \& Colton that the ovulation invariably occurs between 10 th and 14 th days of menstrual cycle. This test needs further confirmation from other tests such as endometrial biopsy carried out simultaneously.
\end{abstract}

\section{INTRODUGTION}

Accurate knowledge of the day of ovulation will be of immense help to a clinician who has to treat large numbers of infertile cases. Various methods are in vogue to detect the precise day of ovulation such as: (1) endometrial biopsy, (2) basal body temperature charts, (3) Papanicolav vaginal smears, (3) electropotential changes, (5) mid-cycle pain or bleeding, (6) tests on cervical mucous, namely Spinnbarkeit and fern test, (7) hormonal estimations, which include estimations of pregnandiol and gonadotrophins, (8) Farris test, (9) detection of glucose in cervical secretions and (10) blood platelet count.

Unfortunately, none of these tests is simple yet accurate, and many of them require experienced personnel for their performance besides involving prohibitive expense. Recently, Sevag \& Colton (1959) have reported a simple chemical test and in this paper we are recording our preliminary observations with the same.

\section{MATERIAL AND METHOD}

We have carried out this test on infertile women who attended the Family Welfare Bureau during last year. One hundred and twelve menstrual cycles of sixty women were studied. In six cases, four menstrual cycles of each were studied. In ten cases, three menstrual cycles of each were studied. In fourteen cases, two menstrual cycles of each were studied and in thirty cases, one menstrual cycle of each was studied. Prior to submitting these patients for this test, it is needless to mention that we had carried out all the routine diagnostic investigations including endometrial biopsies. Only those women who were having ovulatory menstrual cycles were selected for the present study. 
In spite of our patients being illiterate, we could succeed in keeping the records of basal body temperature charts in sixty-three menstrual cycles.

To establish the validity of the ovulation day arrived at by the chemical test in unequivocal terms, we have performed endometrial biopsies in ten cases within 24 to $48 \mathrm{hr}$ after the speculated day of ovulation.

\section{Interpretation of readings}

The ovulation pattern can be identified easily from Text-fig. 1. It has the appearance of a triangle with a base extending for 5 to 6 days of the menstrual cycle. It begins with the lowest colorimetric reading, followed by a gradual rise to the peak, followed by an abrupt, gentle or gradual drop in the colorimetric readings. The highest peak in the ovulation patterns may be either reached on the 2 nd, 3rd or 4th day from the beginning of the phase. The ovulation day is

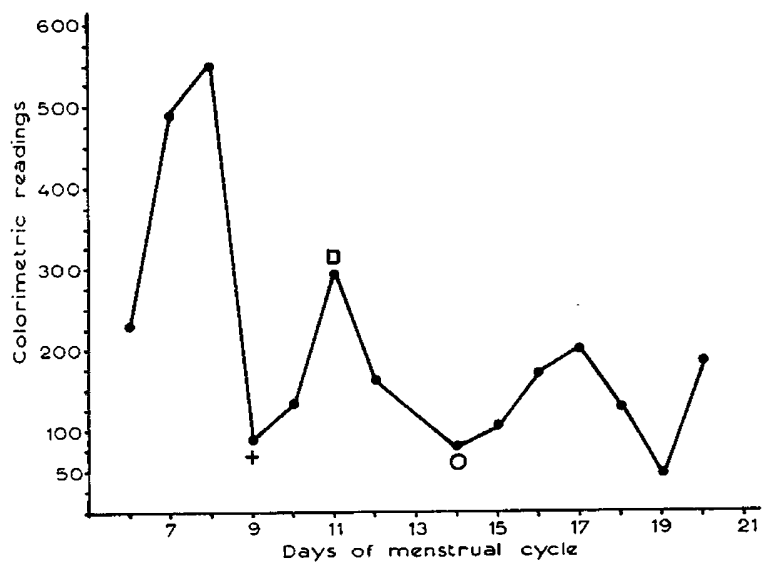

Text-FIG. 1. (R.B. No. 1914). A case showing the typical ovulatory pattern in the Sevag-Colton test. + and $\square=$ beginning and peak, respectively, of ovulatory pattern. $\mathrm{O}=$ probable day of ovulation.

identified by the terminal low point which is preceded by a triangular pattern, and which should fall on the 5 th or the 6 th day from the beginning of the ovulation pattern.

Though in the vast majority of cases the ovulation pattern extends for 5 to 6 cycle days, in the minority of cases it may be of 4 days or 7 days duration. Generally the day of ovulation occurs in between the 10th and 14th days of the menstrual cycle.

\section{RESULTS}

The results obtained by Sevag \& Colton are very encouraging. They have reported 227 conceptions out of which, in 149 cases, the day of ovulation was ascertained by chemical method alone. In their series, 54.5\% pregnancies occurred in the 1st month during which period the woman had either a single coitus or insemination. The highest number of pregnancies $(90.2 \%)$ occurred when inseminations were carried out on the 5 th and 6 th day of the ovulation 
pattern. In Table 1, we have summarized the data regarding the duration of ovulation patterns in our series as compared to the Sevag \& Colton series.

TABLE 1

DURATION OF THE OVULATION PATTERN

\begin{tabular}{l|c|c}
\hline & $\begin{array}{c}\text { Sevag E Colton } \\
\text { series } \\
(\%)\end{array}$ & $\begin{array}{c}\text { Our series } \\
(\%)\end{array}$ \\
\hline 4 days ovulation pattern & $4 \cdot 0$ & $5 \cdot 4$ \\
5 days ovulation pattern & $53 \cdot 6$ & $48 \cdot 2$ \\
7 days ovulation pattern & $36 \cdot 0$ & $35 \cdot 7$ \\
\hline days ovulation pattern & $6 \cdot 7$ & $10 \cdot 7$ \\
\hline
\end{tabular}

\section{Pregnancies}

We have carried out artificial inseminations with husband's semen in twentytwo patients. Conception occurred in three cases only. While evaluating these results, one must consider the fact that in eight cases either the sperm count was very poor, i.e. below 10 millions $/ \mathrm{cm}^{3}$ or the motility of spermatozoa was exceedingly low. These three conceptions have impartially occurred on the 4th, 5th and 6th days of ovulation patterns. One such case is illustrated in Text-fig. 2.

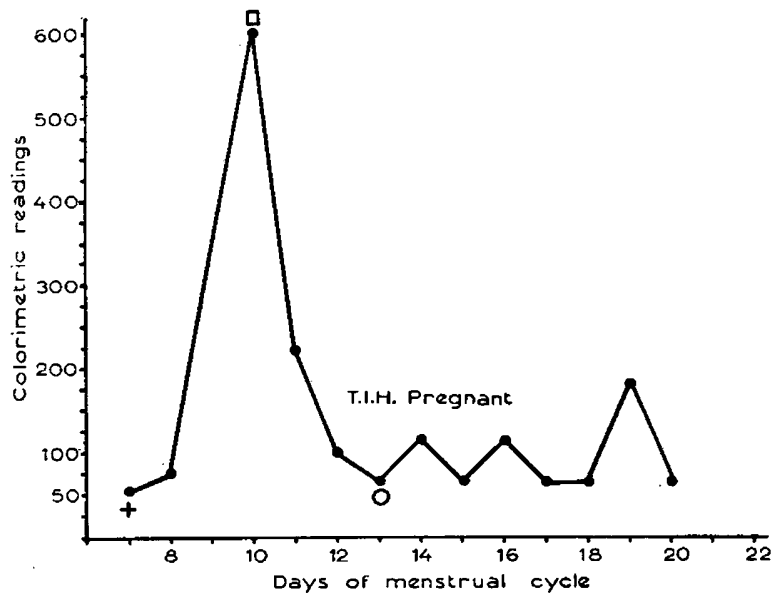

Text-Fig 2. (R.B. No. 2033). Observations made in a case in which artificial insemination with the husband's semen on Day 14 resulted in pregnancy. Symbols as in Text-fig. 1.

\section{Day of ovulation}

In Sevag's series, the day of ovulation invariably occurred between the 10th and 14th days of menstrual cycle. In our series, the ovulation day occurred, according to the chemical test, in this range in $53.6 \%$ cases.

In other cases where the day of ovulation had occurred on 16th, 17th or 18th day of menstrual cycle, the length of the menstrual cycle remained unchanged. 
Typical ovulation patterns and their variants

Out of 112 menstrual cycles studied, typical ovulation patterns were observed in twenty menstrual cycles, i.e. in $17.9 \%$ cases. In thirty-six menstrual cycles $(32 \cdot 1 \%)$, the ovulation pattern had no triangular appearance but was $\mathbf{M}$

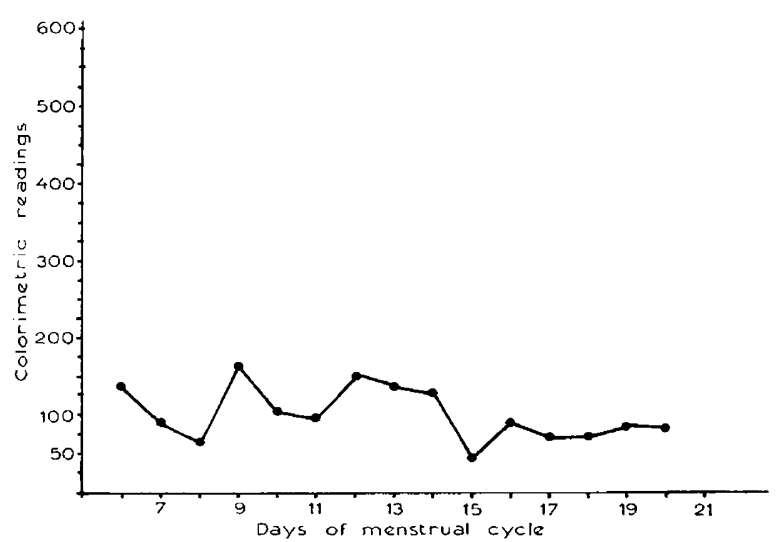

Text-FIG. 3. (R.B. No. 1993). A case in which the day of ovulation could not be surmized.

shaped. These have been labelled as atypical but acceptable. In the remaining fifty-six menstrual cycles, the graphical patterns were more bizarre and no conclusion could be reached as to which was the precise day of ovulation. For

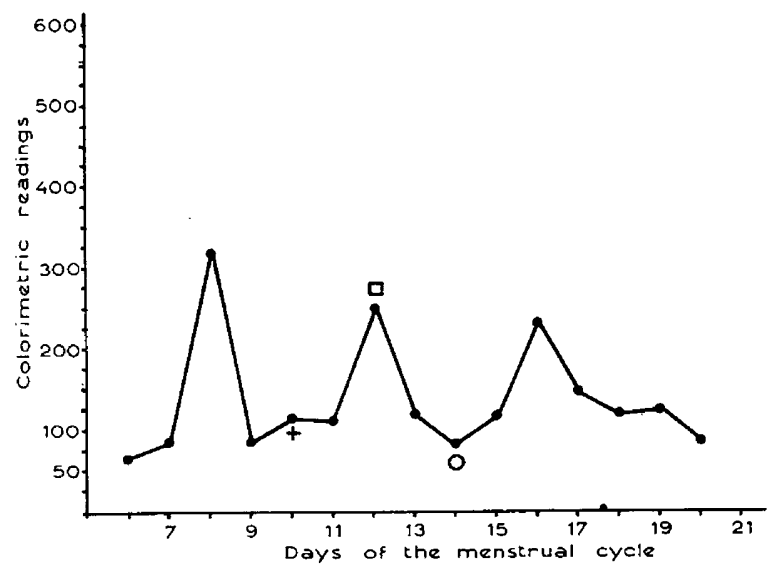

TExT-FIG. 4. (R.B. No. 1700) Observations here showed three apparent ovulatory patterns. Symbols as in Text-fig. 1.

example, in Text-fig. 3 the whole pattern is irregular and no conclusion can be reached as to which is the probable day of ovulation.

The difficulty is further enhanced when one encounters a pattern as illustrated in Text-fig. 4. In this pattern, the 10th, 14th or 18th days could all be taken as ovulation days. The only rationale in selecting the middle triangle is the 
observed fact that the day of ovulation invariably occurred according to Sevag $\&$ Colton in the range of the 10th to 14th day of the menstrual cycle. The same difficulty is experienced when one comes across a graph like the one illustrated in Text-fig. 5. It shows that the ovulation day could be either on the 13th or 18 th day of the menstrual cycle.

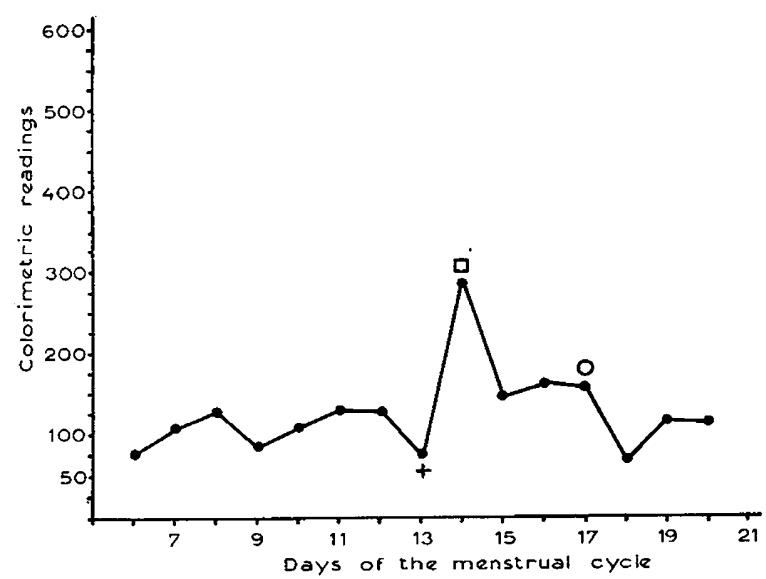

Text-Fig. 5. (R.B. No. 1554). Another example of a somewhat ambiguous result. Symbols as in Text-fig. 1.

Text-fig. 6 illustrates the readings in a case who had anovulatory cycles. Endometrial biopsy was performed on the 12th and 17 th days of the menstrual cycle, which showed proliferative phase of the endometrium.

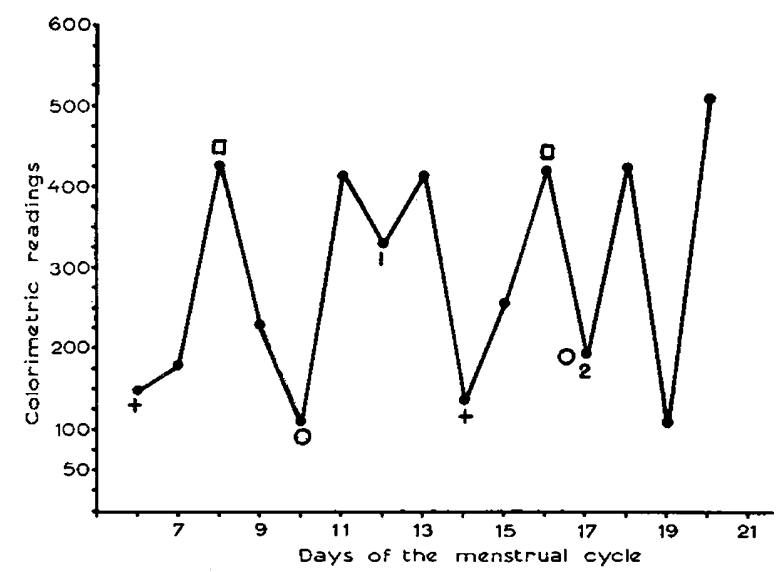

Text-Fig. 6. (R.B. No. 653). Readings in a case with anovulatory cycles. At 1 and 2, biopsy specimens showed that the endometrium was in the proliferative phase. Other symbols as in Text-fig. 1 .

Hence, we decided to carry out an endometrial biopsy 24 to $48 \mathrm{hr}$ after the speculated day of ovulation. We expected to find the endometrial biopsy picture corresponding to 2 nd or 3rd post-ovulatory day. The criteria used in dating the endometrium are those of Noyes, Hertig \& Rock (1950). 
In Text-fig. 7, the pattern of colorimetric readings was confusing. The day of ovulation in this patient could be either the 13th or the 18th day. We had carried out endometrial biopsy on the 16th day, which showed late proliferative phase of the endometrium, thereby indicating that no ovulation had occurred

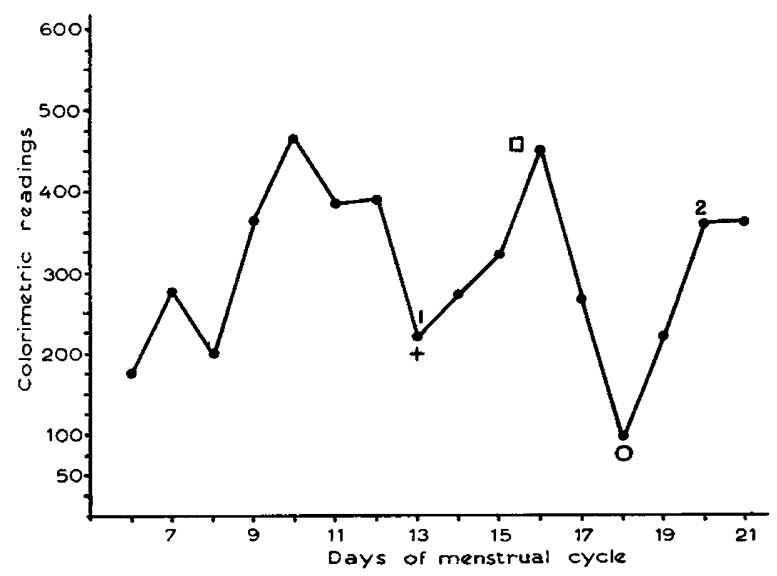

Text-Fig. 7. (R.B. No. 2346). Another rather ambiguous result. At 1 and 2, biopsy specimens showed that the endometrium was in the late proliferative and early secretory phases, respectively. Other symbols as in Text-fig. 1.

during the preceding triangular pattern. Then we suspected that the ovulation day could be the 18th day. So we performed the endometrial biopsy again on the 20th day. It showed the picture typical of the mid-secretory phase of the

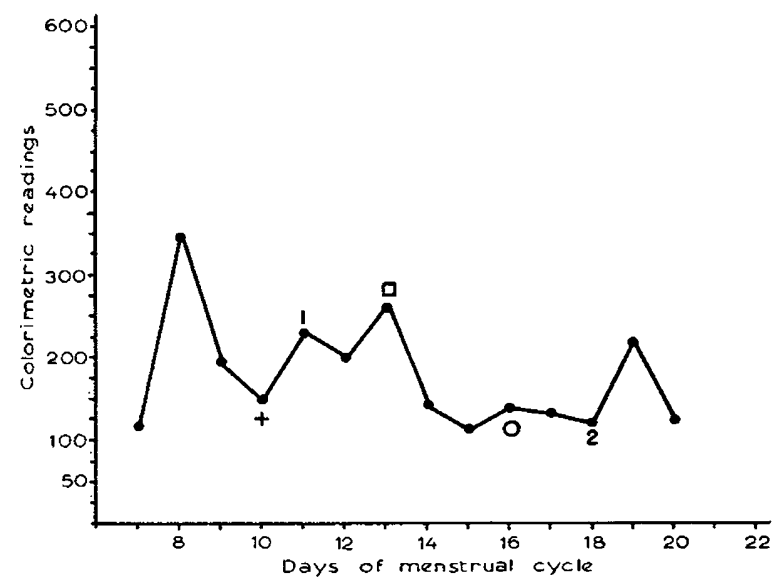

TEXT-FIG. 8. (R.B. No. 529). Showing the M-shaped pattern which, though atypical in the Sevag-Colton test, may serve to indicate the day of ovulation. At 1 , biopsy specimen showed the endometrium to be in the late proliferative phase and at 2 it showed a picture corresponding to the 2nd post-ovulatory day. Other symbols as in Text-fig. 1

endometrium where the gland nuclei had lined up because of uniform basal subnuclear vacuolation, mitosis and pseudostratification was absent. This picture corresponds to the 3rd post-ovulatory day and indirectly confirms that the ovulation has occurred on the 18th day. 
In Text-fig. 8, the initial triangular pattern from the 7th to 10th day was not an ovulation pattern, because endometrial biopsy done on the 11 th day showed proliferation of endometrium. The subsequent $M$-shaped pattern, though atypical, was ovulation pattern, as the endometrial biopsy done on the 18th day showed a picture corresponding to the 2 nd post-ovulatory day. It showed the beginning of irregular subnuclear vacuolation in the glandular epithelium. The pseudostratification of the nuclei was more marked and an occasional mitosis could be identified in the glandular epithelium. The stroma was dense. It indirectly confirmed the ovulation pattern which was atypical.

In both these instances, ovulation occurred on the 16th and 18th day, respectively. Recently, we have started a routine of carrying out the endometrial biopsy 24 to $48 \mathrm{hr}$ after the speculated day of ovulation.

We can not substantiate the claim of Sevag \& Colton that ovulation generally occurs in the range of the 10th to 14th days of the menstrual cycle.

Similarly our readings are on the lower side. The hypothesis that ovulation generally occurs 14 days prior to the onset of the next menstrual period was not confirmed by the findings of the chemical test. Out of 112 cycles studied, this hypothetical day of ovulation coincided only in sixteen cases with the speculated day of ovulation obtained as by the chemical test.

Out of sixty-three basal body-temperature charts studied, the point of thermal shift and the ovulation day as derived by the chemical test coincided in nine cases only.

\section{GONCLUSION}

In our hands, the typical ovulation patterns were observed in the minority of cases. When there are multiple triangular patterns in one menstrual cycle, the assessment of the day of ovulation requires supplementary tests. Further studies and tests which will check the findings of the chemical tests are indicated. We feel that the endometrial biopsy, which is performed within 24 to $48 \mathrm{hr}$ after the speculated day of ovulation, will provide a direct valid check on the findings of the chemical test.

\section{ACKNOWLEDGMENT}

We are thankful to Dr G. M. Phadke, F.R.G.s., Director, Family Welfare Bureau, for his constructive criticism and guidance.

\section{REFERENCES}

Behrman, S. J. (1960) Detection of ovulation. Postgrad. Med. 27, 1.

Noyes, R. W., Hertic, A. T. \& Rock, J. (1950) Dating the endometrial biopsy. Fertil. \& Steril. $1,3$.

SevaG, M. G. \& Colton, S. W. (1959) Simple chemical method for the determination of ovulation time in women. F. Amer. med. Ass, 170, 13. 